IRAOI JOURNAL of $\mathbf{E}_{\text {MBRYOS AND }} I_{\text {NFERTILTY }} \boldsymbol{R}_{\text {ESEARCHES }}$

Dawood, et al., Vol. 10, Issue 1, Pp. 35-50 (2020)

(IJEIR)

DOI: http://doi.org/10.28969/IJEIR.v10.i1.r3

Original Research

E-ISSN: 2616-6984 P-ISSN: 2218-0265

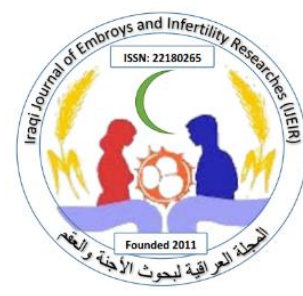

\title{
A Comparison Between the Effect of Vaginal Sildenafil Versus Oral Estradiol Valerate on Ultrasound Parameters of Endometrial Receptivity and Follicular Growth in Iraqi Females Receiving Letrozole for Induction of Ovulation
} Received: 14-Jul-2020 Accepted: 31-Aug-2020 Published: 14-Dec-2020

\section{Sundus Ali Dawood $^{1}$, Mufeda Ali Jwad ${ }^{1}$, Huda Ali Hussaini ${ }^{2}$}
${ }^{1}$ High Institute of Infertility Diagnosis and Assisted Reproductive Technologies, Al Nahrain University, Baghdad, Iraq. dr.sundus7@ gmail.com
${ }^{2}$ College of Medicine, Al Nahrain University, Baghdad, Iraq.

Endometrial thickness (ET) is one of the best predictors of implantation rate and pregnancy success rate because endometrial growth depends on hormones. Estrogen regulates the proliferative phase, endometrial proliferation induced by estrogen after menstruation is largely dependent on blood flow to the basal endometrium that produces progesterone receptors which are required for progesterone-regulated endometrial growth in the secretory process. To compare the effect of estradiol valerate vs. sildenafil citrate on endometrial receptivity and subsequent pregnancy outcome in unexplained infertility patients receiving letrozole for ovulation induction. Herein, 21 patients with unexplained infertility underwent ovulation induction by letrozole $(2.5 \mathrm{mg})$. Patients were divided into 2 groups; group A (10 patients) were given sildenafil tablets vaginally $(25 \mathrm{mg}$ ) four times daily and group B (11 patients) were treated with estradiol valerate tablet $2 \mathrm{mg} / 12$ hours. Patients were evaluated by transvaginal ultrasonography (TVS) to determine endometrial thickness, pattern, size, and the number of the dominant follicles, serum assessment of Vascular Endothelial Growth Factor (VEGF) level at trigger day, and chemical pregnancy outcome 14 days later. Results showed that the endometrial thickness, patterns of the endometrium, VEGF, size of the dominant follicle at the trigger day, and pregnancy rates were not significantly different between the two groups. However, the difference in the number of the dominant follicles at trigger day was statistically significant which is more in the sildenafil treated group. The present study confirmed the findings of both Sildenafil and $\mathrm{E}_{2}$ valerate to boost endometrial receptivity and pregnancy rate.

Keywords: Estradiol valerate; Sildenafil citrate; Endometrial receptivity. 


\section{Introduction}

Letrozole is just as effective for ovulation induction as clomiphene citrate in patients with unexplained infertility (Eskew, et al. $\left.{ }^{[1]}\right)$. It is an orally active inhibitor of aromatase enzyme with strong potential for induction of ovulation. Several researchers have studied this drug as a choice to induce ovulation (Kar $S,{ }^{[2]}$ ). Aromatase enzyme inhibition causes a reduction in estrogen levels believed to result in more follicle-stimulating hormone $(\mathrm{FSH})$ production, resulting in follicular growth (Requena, et al. ${ }^{[3]}$ ). Inhibitors of aromatase enzymes also cause a local increase in ovarian androgens that increases follicular sensitivity to FSH and stimulates insulin-like growth factor-1 (IGF-I) (Usluogullari, et al. ${ }^{[4]}$ ). Effective implantation of an embryo in all organisms requires a receptive endometrium, good embryo quality, and synchronization of endometrial growth with embryos. Ultrasonography markers like endometrial thickness, pattern, blood flow, and biochemical markers are often used to assess endometrial receptivity during the implantation window (Teh, et al. $\left.{ }^{[5]}\right)$. A sufficiently thickened endometrium is an important factor for implantation of embryos and can predict the outcome of pregnancy with high specificity and sensitivity (Zhang, et al. ${ }^{[6]}$ ). In addition, many studies recorded a strong positive association between a $7 \mathrm{~mm}$ (preferably > $9 \mathrm{~mm}$ ) triple-layer thickened endometrium and pregnancy rate (Moini, et al. ${ }^{[7]}$ ).

\subsection{Estrogen}

The endometrium, which is tissue dependent on hormones, proliferates in response to estrogen hormone which additionally induces the production of progesterone receptors. As a result, treatments for estradiol $\left(E_{2}\right)$ are offered to infertile patients with thin endometrium, in an attempt to increase endometrial proliferation. The majority of estradiol clinical studies in patients with a thin endometrium dealt with frozen embryo transfer attempts, endometrial proliferation caused by estrogen relies primarily on blood flow to the basal 
endometrium (Sher, et al. ${ }^{[8]}$ ). Chen et al. studied the effect of prolonged estradiol valerate treatment during controlled ovarian hyperstimulation cycles and found that the average endometrial thickness in the treatment group increased after treatment and also rate of pregnancy increased more than in the control group (Chen, et al. ${ }^{[9]}$ ).

\section{$1.2 \quad$ Sildenafil}

Vaginal sildenafil citrate has been tried in the treatment of patients with recurrent implantation failure. Sildenafil citrate is an effective and selective inhibitor of phosphodiesterase-5 (PDE-5). This improves the vasodilatory effect of nitric oxide by preventing the degradation of cyclic guanosine monophosphate (cGMP), leading to vascular relaxation and improved uterine blood flow, and increasing endometrial receptivity. This results in relaxation of the vasculature and enhanced blood flow and increased endometrial thickness (AbdelKader, et al. $\left.{ }^{[10]}\right)$. The implantation accomplished relies on the blastocyst's capacity to invade the endometrium and create blood supply, which demands the genes to produce the proteins necessary to digest the matrix of endometrial cells, control cell growth, and provoke angiogenesis for example tumor suppressor factor (p53), plasminogen activator inhibitor 1 (PAI-1) and vascular endothelial growth factor (VEGF) ( $D$ Ly

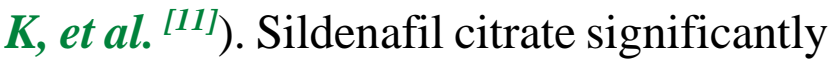
increased p53 and angiogenic responses with enhanced VEGF (Di X, et al. ${ }^{[12]}$ ). The potential, even promising, functional markers of endometrial receptivity are invasive and expensive. Therefore, Transvaginal ultrasonography has been suggested as an alternative approach in endometrial receptivity assessment. It was reported that endometrial thickness and pattern on HCG day might be a prediction of pregnancy success (Naha, et al. ${ }^{[13]}$ ). Hence this study aims to estimate the effect of estradiol $\left(E_{2}\right)$ vs sildenafil citrate on endometrial receptivity in infertile female patients taking letrozole using grayscale ultrasound. 


\section{Materials and Methods}

The present study is a comparative prospective study which was carried out at the High Institute of Infertility Diagnosis and Assisted Reproductive Technologies, Al Nahrain University, Baghdad, Iraq. Over a period of eight months (July 2019 until March 2020) including 21 women with unexplained, primary, or secondary infertility. The study was approved by the ethics committee of the Institute. The patients who participate in this study had received informed consent and the details, advantages, and risks have been explained to them. The age of females included in the present study was less than 40 years (1839 years). The exclusion criteria were as follows: female over 40 years of age, have severe endometriosis, any uterine congenital anomaly or acquired uterine cavity deformities that interfere with implantation (like Asherman Syndrome), Large submucosal intramural fibroid, estrogen therapy contraindications (e.g., history of DVT, stroke, and Benign liver disease), female who have tubal factors that may interfere with conception (uni- or bilateral hydrosalpinx), Thyroid disease, Male infertility factor according to seminal fluid analysis parameters. Hysterosalpingography (HSG) and ultrasound analysis were performed for every patient to assess the uterus, endometrium, ovaries, and patency of fallopian tubes. All patients underwent ovulation induction by Letrozole (Femara®, Novartis, Basel, Switzerland) orally $2.5 \mathrm{mg}$ every 12 hours from the $3^{\text {rd }}$ day for 5 days of the menstrual cycle. The patients with thin endometrium were randomly distributed into two groups. In group A, 10 patients were included and given sildenafil citrate $25 \mathrm{mg}$ (Viagra, Pfizer Inc., New York, USA) vaginally every 6 hours from the $6^{\text {th }}$ day of the cycle. In group B, 11 patients were given estradiol valerate (estrofem, Novo Nordisk) 2 mg every 12 hours. Follow up by serial transvaginal sonography that was done at $7^{\text {th }}$ day of the cycle and after that 2-3 days interval according to endometrial thickness, regularity, and number, size of 
follicles, when at least one follicle reaches the size $17 \mathrm{~mm}$ or more on cycle day 1113 , then the trigger was given which was urinary HCG (5,000 IU, Pregnyl, Organon, Netherlands). Ultrasound examination have been done for assessing endometrial morphology (thickness and pattern), Endometrial pattern was classified as a triple-line pattern (consisting of a central hyperechoic line surrounded by two hypoechoic layers), or homogenous pattern (hyperechogenic endometrium). (Zhao, et al. ${ }^{[14]}$ ) as shown in Figure 1. The endometrium thickness as shown in Figure 2 is known as the maximum distance in the longitudinal plane of the uterus between the two endometrium myometrium junction interfaces (Fang, et al. $\left.{ }^{[15]}\right)$. Also, the number and size of Graafian follicles have been measured by mean follicular diameter (mean of two orthogonal diameter measurements) reaching $\geq 17 \mathrm{~mm}$. as shown in Figure 3 . Blood samples were taken from all patients for measuring the level of vascular endothelial growth factor in the serum.
Then, timed intercourse (24-36 hours after hCG injection) was advised. Three days later, the luteal phase was supported by vaginal progesterone (Cyclogest, Actavis, $\mathrm{UK}, 400 \mathrm{mg}$ ). After 14 days $\beta$ hCG test was done in the blood to check pregnancy.

\section{Statistical Analysis}

The collected data were coded, tabulated, and statistically analyzed by Microsoft Excel 2016, and Statistical Package for Social Sciences (SPSS) version 22.0 was used. Data are presented as mean \pm standard deviation. The groups were compared by the student's paired t-test, chi-square, and ANOVA. The degree of association between continuous variables was calculated by Pearson's correlation coefficient (r). The significance level was assumed at $\mathrm{P}<0.050$.

\section{Results}

Twenty-one patients with primary or secondary infertility were included in the present study, all patients had normal HSG and all received letrozole as an 


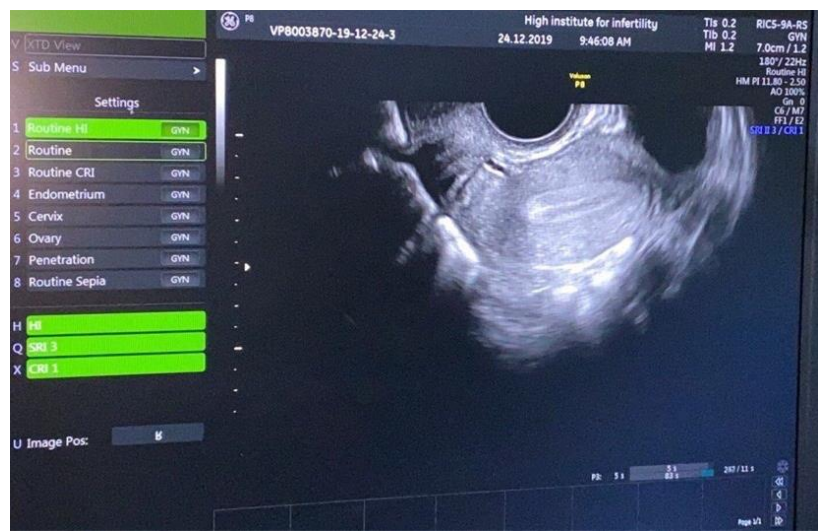

Figure (1): Transvaginal ultrasound of the uterus in the longitudinal plane show triple line pattern CD12

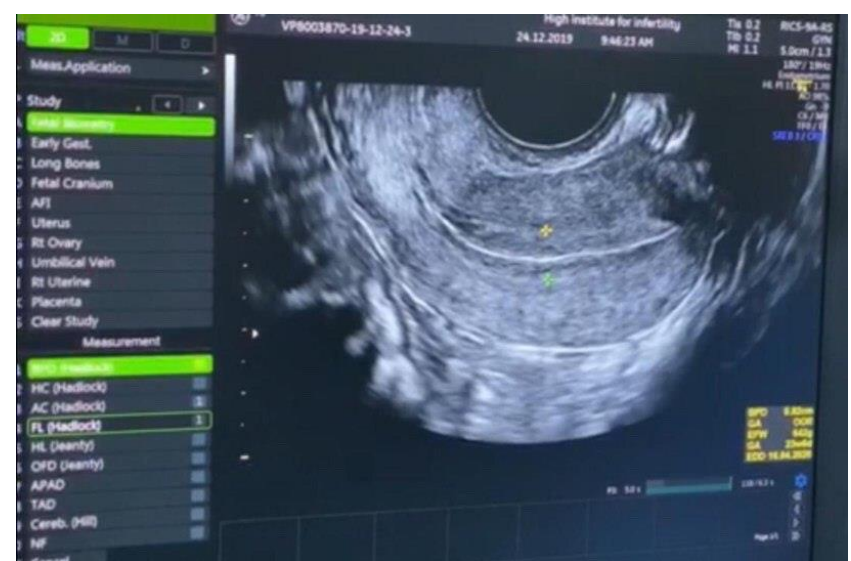

Figure (2): Transvaginal ultrasound of the uterus in the longitudinal plane. Cursors, endometrium (in $\mathrm{mm}$ ) at the thickest point between the two basal layers on the anterior and posterior uterine walls with triple line pattern (CD13)

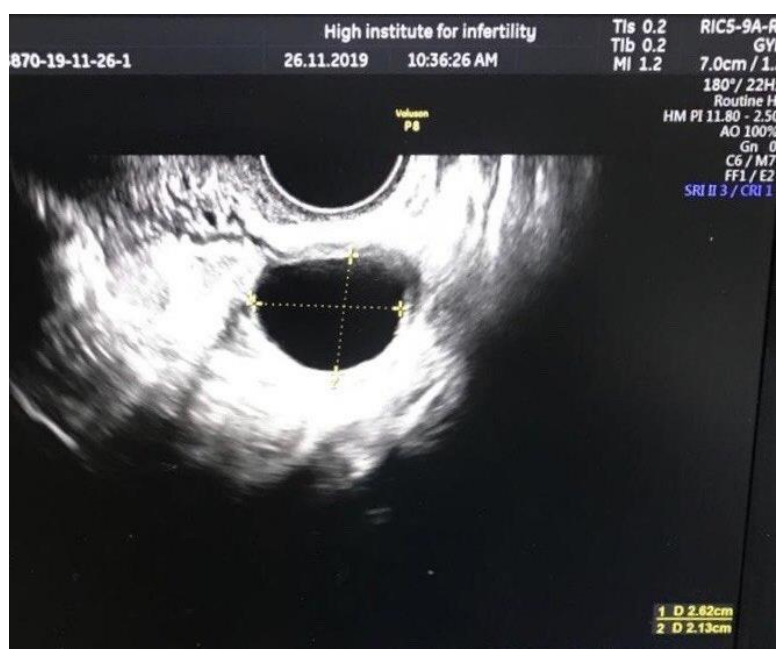

Figure (3): Transvaginal ultrasound of the ovary showing dominant follicle measurement (CD13)

Dawood, et al. http://doi.org/10.28969/IJEIR.v10.i1.r3 
ovulation induction drug and they all had no gynecological problem.

\subsection{Demographic parameters and the} basal hormonal profile

Regarding the demographic parameters (age, BMI of patients, and duration of infertility) were shown in Table 1 and the basal hormonal profile level (FSH, LH, PRL, $\mathrm{E}_{2}$, and TSH) were shown in Table 2 , the statistical analysis showed no significant differences $(\mathrm{P}>0.05)$ between the group who was treated with letrozole plus sildenafil and those who was treated with letrozole plus estradiol valerate.

\subsection{Comparison between endometrial} thickness at the cycle's $7^{\text {th }}$ day and at the hCG trigger's day

There are no significant differences $(\mathrm{P}>0.05)$ between the endometrial thickness (ET) at cycle $7^{\text {th }}$ day between the studied groups also, there are no significant differences between the ET at the day of hCG trigger between the studied groups as shown in Figure 4. In contrast, there was a statistically highly significant difference between endometrial thickness at cycle $7^{\text {th }}$ day and trigger day within the estradiol group $(\mathrm{P} \leq 0.001)$. Also, there was a statistically highly significant difference between endometrial thickness at cycle $7^{\text {th }}$ day and trigger day within the sildenafil group $(\mathrm{P} \leq 0.001)$.

\subsection{Comparison of Ultrasound parameter} and VEGF level at the day of hCG administration

The difference in the number of the dominant follicles at hCG day between studied groups was statistically significant $(\mathrm{P}<0.05)$ which was more in the sildenafil group. However, the difference in the size of the dominant follicles was insignificant $(\mathrm{P}>0.05)$ between the studied groups. The mean endometrial thickness at the day of hCG administration was $8.63 \mathrm{~mm}$ in the sildenafil plus letrozole treated group while in the estradiol plus letrozole treated group it was $8.94 \mathrm{~mm}$. Even though the endometrium was found to be thicker in 
Table (1): Comparison of demographic parameters of infertile patients

\begin{tabular}{|c|c|c|c|}
\hline Parameters & $\begin{array}{c}\text { Sildenafil group } \\
\mathbf{N}=(\mathbf{1 0}) \\
\text { (Mean } \mathbf{\text { SD}})\end{array}$ & $\begin{array}{c}\text { Estradiol group } \\
\mathbf{N}=\mathbf{( 1 1 )} \\
\text { (Mean } \pm \text { SD) }\end{array}$ & $\boldsymbol{P}$-value \\
\hline Age (years) & $31.6 \pm 5.6$ & $28.49 \pm 6.2$ & 0.08 \\
\hline BMI (Kg/m $\mathbf{2})$ & $28.49 \pm 2.51$ & $27.43 \pm 1.98$ & 0.07 \\
\hline $\begin{array}{c}\text { Duration of } \\
\text { infertility (years) }\end{array}$ & $3.06 \pm 1.83$ & $2.23 \pm 1.56$ & 0.06 \\
\hline
\end{tabular}

Table (2): Comparison of hormonal levels of infertile patients

\begin{tabular}{|c|c|c|c|}
\hline Parameter & $\begin{array}{c}\text { Sildenafil group } \\
\text { N=(10) } \\
(\text { Mean } \pm \text { SD) }\end{array}$ & $\begin{array}{c}\text { Estradiol group } \\
\text { N=(11) } \\
(\text { Mean } \pm \text { SD) }\end{array}$ & P-value \\
\hline Prolactin & $7.73 \pm 2.90$ & $7.49 \pm 2.97$ & 0.75 \\
\hline $\boldsymbol{F S H}$ & $6.88 \pm 2.82$ & $6.29 \pm 2.67$ & 0.41 \\
\hline $\boldsymbol{T S H}$ & $2.29 \pm 0.873$ & $1.97 \pm 1.07$ & 0.21 \\
\hline $\boldsymbol{E}$ & $43.35 \pm 12.02$ & $44.31 \pm 29.95$ & 0.87 \\
\hline $\boldsymbol{L H}$ & $7.02 \pm 2.81$ & $6.63 \pm 2.26$ & 0.56 \\
\hline
\end{tabular}

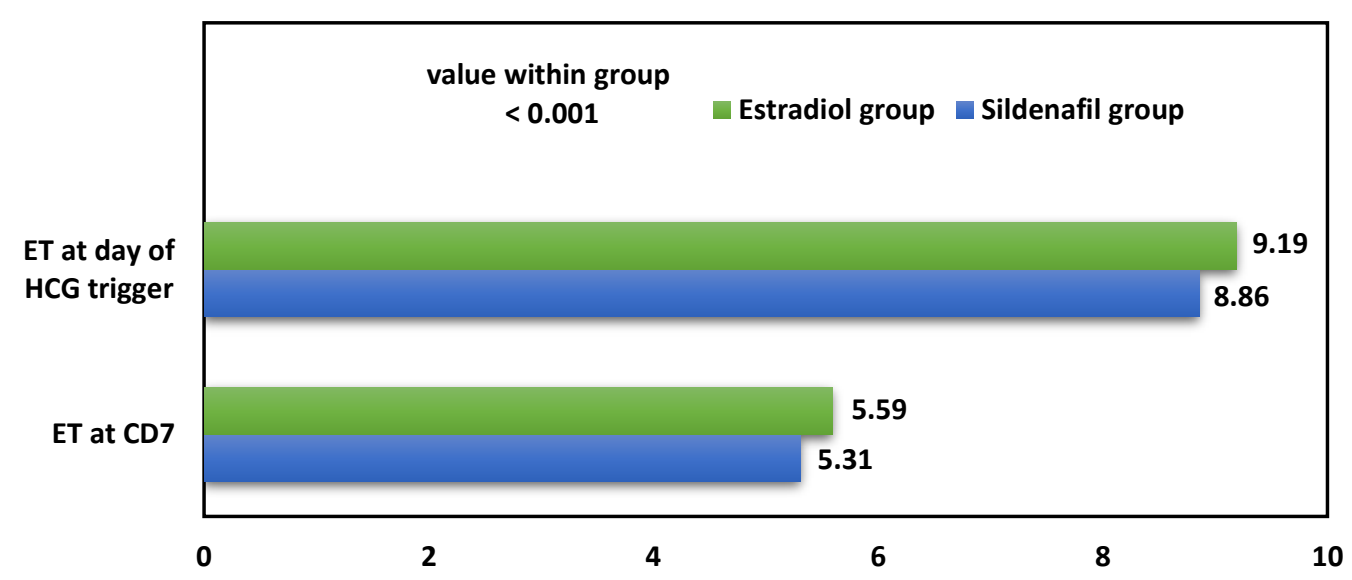

Figure (4): Comparison between endometrial thickness at cycle's $7^{\text {th }}$ day and at day of HCG trigger 
Table (3): Comparison of ultrasound finding and VEGF between studied groups

\begin{tabular}{|c|c|c|c|}
\hline Parameter & $\begin{array}{c}\text { Sildenafil group } \\
\mathbf{N = 1 0}\end{array}$ & $\begin{array}{c}\text { Estradiol group } \\
\boldsymbol{N}=\mathbf{1 1}\end{array}$ & P-value \\
\hline ET at CD7 & $5.24 \pm 0.56$ & $5.32 \pm 0.77$ & 0.11 \\
\hline $\begin{array}{c}\text { ET at day of HCG } \\
\text { trigger }\end{array}$ & $8.63 \pm 0.42$ & $8.94 \pm 0.68$ & 0.23 \\
\hline $\begin{array}{c}\text { Pattern Triple layer } \\
\text { Mono layer }\end{array}$ & $\begin{array}{c}8(80 \%) \\
\text { VEGF }\end{array}$ & $\begin{array}{c}11(100 \%) \\
0\end{array}$ & 0.11 \\
\hline Size offollicles & $19.84 \pm 1.8$ & $18.95 \pm 2.01$ & 0.87 \\
\hline Number of follicles & $1.5 \pm 0.53$ & $1.09 \pm 0.30$ & 0.04 \\
\hline PR & 4 & 1 & 0.09 \\
\hline
\end{tabular}

the estradiol group, the results were statistically insignificant $(\mathrm{P}>0.05) .80 \%$ of patients in the sildenafil group and $100 \%$ in the estradiol group developed a trilaminar pattern of the endometrium. There were no significant differences ( $\mathrm{P}>0.05)$ between sildenafil and estradiol treated groups. Regarding the mean VEGF level which was 217.2, 218.9 respectively $(\mathrm{P}>0.05)$ as shown in Table 3.

\subsection{Pregnancy rates}

The biochemical pregnancy rates were four in group 1 and one in group 2 (P>0.05) which is insignificant (Table 3).

\section{Discussion}

5.1 Endometrial receptivity and pregnancy rate

In the present study, the endometrial thickness and pattern were assessed at the trigger day, which was enhanced in both estradiol and sildenafil combination with letrozole. However, the pregnancy rate did not show any substantial difference between the groups studied. Several studies have investigated the function of sildenafil citrate in improving blood flow and endometrial thickness in patients with a history of reproductive failure due to low endometrial response (Ataalla, et al. ${ }^{[16]}$; Mangal and Mehirishi, $\left.{ }^{[17]}\right)$. The present findings were identified by Ataalla, et al. 
who argued that the oral use of sildenafil may be a safe way of enhancing endometrial receptivity and pregnancy rate (Ataalla, et al. ${ }^{[16]}$ ). Moini et al. confirmed in his randomized placebocontrolled trial study that vaginal sildenafil is believably increased chemical pregnancy rate in females with a history of IVF failure (a 2-fold increase compared with placebo); however, still no noticeable difference in endometrial thickness between groups on HCG injection day (Moini, et al. ${ }^{[7]}$ ). Mangal and Mehirishi concluded in a comparative prospective study that the rate of pregnancy in the female who underwent intrauterine insemination (IUI) cycles who used vaginal sildenafil was significantly higher than in the group who used estradiol valerate (Mangal and Mehirishi, ${ }^{[17]}$ ). The findings from a retrospective study by Margreiter et al. showed a substantial enhancement in the rate of implantation, endometrial thickness, and pregnancy, and diminished abortion in the group of vaginal sildenafil treated females
(Margreiter, et al. ${ }^{[18]}$ ). For a prospective study on fifty females with unexplained primary infertility, El-Shourbagy et al were administered sildenafil citrate suppositories $25 \mathrm{mg}$ of 4 times daily for 7 days. Patients treated with sildenafil citrate demonstrate a significant rise in endometrial thickness and a higher pregnancy outcome compare with the control group receiving no treatment $(E \mathbf{E}$ Shourbagy, et al. $\left.{ }^{[19]}\right)$. The findings of this study coincided with preceding research regard sildenafil's effect on endometrium and pregnancy outcome. Çetinkaya, and Kadanalı used $25 \mathrm{mcg}$ of local vaginal estrogen from the fourth day for two weeks in patients undergoing a clomiphene citrate cycle; on day of ovulation, they reported a significant growth in endometrial thickness is relative to the group where only clomiphene citrate was used although there was no change in pregnancy rate (Cetinkaya and Kadanall, $\left.{ }^{[20]}\right)$. The results of a metaanalysis conducted by Torres et al. investigated the use of Ethinyl estradiol 
for thin endometrium improves endometrial thickness compared to patients using placebo only (Torres, et al. $\left.{ }^{[21]}\right)$. Therefore, most of these studies further support the results of the present study. However, most of the previous work had compared estradiol or sildenafil alone with the patient's previous cycle used as control. Several studies have also been published, comparing estradiol and sildenafil to estradiol alone.

\subsection{Dominant follicles count and size at} the day of hCG trigger

When letrozole was used as ovulation induction, the mean number of mature follicles differed significantly; in sildenafil women, it was higher than in estradiol patients as presented in Table 3 . This result may lead to the thought that the relationship between sildenafil and ovarian function may be important. It is probable that due to sildenafil was administered locally, it may produce an increase in the blood flow of the overall female genital tract including the ovaries with consequent improvement of ovarian follicle development. Good uterine and ovarian blood perfusion may influence the effectiveness of assisted reproductive therapy. Nitric Oxide (NO) relaxes the vascular smooth muscle through a cyclic guanosine monophosphate (cGMP) mediated pathway. A type 5-specific phosphodiesterase inhibitor, sildenafil citrate enhances the vasodilatory effects of NO by stopping cGMP from degrading. The basis of this research is to use sildenafil's vasodilator effect to enhance the ovarian blood flow and that is in turn increase ovarian response to stimulation in women with infertility. In one experimental research, it has been concluded that sildenafil administration can, however, insignificantly increase ovarian angiogenesis (Golkar, et al. ${ }^{[22]}$ ). Trakakis, et al. reported a case of a 37year-old woman who failed to show any follicular development during control ovarian hyperstimulation $(\mathrm{COH})$ in an ICSI cycle but developed ten oocytes in a second cycle after adding sildenafil $50 \mathrm{mg}$ 
daily for a total of five dosages. They recognized that overcome poor ovarian response by the adjuvant sildenafil during $\mathrm{COH}$ (Trakakis, et al. ${ }^{[23]}$ ). This may be explained by the fact that the subsequent administration of vaginal sildenafil enters the uterine blood system directly at a higher concentration and then absorbed into the general circulation it dilutes out.

\section{Conclusions}

To sum up, an appropriately thick, trilaminar endometrial pattern is important for embryo implantation and pregnancy continuation. Both estradiol and sildenafil may be used to improve the endometrium (thickness and vascularity) and to promote embryo development. Sildenafil has increased the dominant follicle counts in patients experiencing a stimulated cycle compared to estradiol valerate. This can be explained by the increase in the blood flow of the total female genital tract along with the ovaries generated by local administration of sildenafil. with subsequent improvement of ovarian follicle growth.

\section{Acknowledgment}

We would like to acknowledge Al Nahrain University, Baghdad, Iraq.

\section{Funding}

This work received no funding.

\section{Author Contribution}

Dawood, SA performed the study, examined and reviewed results, and manuscript writing with the help and supervision of Jwad, MA, and Hussaini, HA.

\section{Conflict of Interest}

The authors declare no conflict of interest.

\section{Ethical Clearance}

The study was approved by the Ethical Approval Committee.

\section{References}

[1] Eskew AM, Bedrick BS, Hardi A, Stoll CR, Colditz GA, Tuuli MG, Jungheim ES. Letrozole compared with clomiphene citrate for unexplained 
infertility: A systematic review and meta-analysis. Obstetrics \& Gynecology. 2019 Mar 1;133(3):43744. [Online Article Link]

[2] Kar S. Clomiphene citrate or letrozole as first-line ovulation induction drug in infertile PCOS women: A prospective randomized trial. Journal of human reproductive sciences. 2012 Sep;5(3):262. [Online Article Link]

[3] Requena A, Herrero J, Landeras J, Navarro E, Neyro JL, Salvador C, Tur R, Callejo J, Checa MA, Farré M, Espinós JJ. Use of letrozole in assisted reproduction: a systematic review and meta-analysis. Human reproduction update. 2008 Nov 1;14(6):571-82. [Online Article Link]

[4] Usluogullari B, Duvan CZ, Usluogullari CA. Use of aromatase inhibitors in practice of gynecology. Journal of ovarian research. 2015 Dec;8(1):4. [Online Article Link]

[5] Teh WT, McBain J, Rogers P. What is the contribution of embryoendometrial asynchrony to implantation failure? Journal of assisted reproduction and genetics. 2016 Nov;33(11):1419-30. [Online Article Link]

[6]Zhang T, Li Z, Ren X, Huang B, Zhu G, Yang W, Jin L. Endometrial thickness as a predictor of the reproductive outcomes in fresh and frozen embryo transfer cycles: A retrospective cohort study of $1512 \mathrm{IVF}$ cycles with morphologically goodquality blastocyst. Medicine. 2018 Jan;97(4):e9689. [Online Article Link] [7] Moini A, Zafarani F, Jahangiri N, Sadatmahalleh SJ, Sadeghi M, Chehrazi M, Ahmadi F. The Effect of Vaginal Sildenafil on The Outcome of Assisted Reproductive Technology Cycles in Patients with Repeated Implantation Failures: A Randomized Placebo-Controlled Trial. International Journal of Fertility \& Sterility. 2020 Jan;13(4):289. [Online Article Link]

[8] Sher G, Fisch JD. Effect of vaginal sildenafil on the outcome of in vitro fertilization (IVF) after multiple IVF failures attributed to poor endometrial development. Fertility and Sterility. 2002 Nov 1;78(5):1073-6. [Online Article Link]

[9]Chen MJ, Yang JH, Peng FH, Chen SU, Ho HN, Yang YS. Extended estrogen administration for women with thin endometrium in frozenthawed in-vitro fertilization programs. Journal of assisted reproduction and genetics. 2006 Aug 1;23(7-8):337-42. [Online Article Link]

[10] AbdelKader Fahmy A, ElSokkary M, Sayed S. The value of oral sildenafil in the treatment of female infertility: a randomized clinical trial. Life Sci J. 2015;12(4):78-82. [Online Article Link]

[11] D Ly K, Aziz N, Safi J, Agarwal A. Evidence-based management of 
infertile couples with repeated implantation failure following IVF. Current Women's Health Reviews. 2010 Aug 1;6(3):200-18. [Online Article Link]

[12] Di X, Gennings C, Bear HD, Graham LJ, Sheth CM, White KL, Gewirtz DA. Influence of the phosphodiesterase-5 inhibitor, sildenafil, on sensitivity to chemotherapy in breast tumor cells. Breast cancer research and treatment. 2010 Nov 1;124(2):349-60. [Online Article Link]

[13] Naha M, Khastgir G. Tests for Endometrial Receptivity. Practical Guide in Assisted Reproductive Technology. 2018 Apr 30:121. [Online Article Link]

[14] Zhao J, Zhang Q, Li Y. The effect of endometrial thickness and pattern measured by ultrasonography on pregnancy outcomes during IVF-ET cycles. Reproductive Biology and Endocrinology. 2012 Dec 1;10(1):100 [Online Article Link].

[15] Fang R, Cai L, Xiong F, Chen J, Yang W, Zhao X. The effect of endometrial thickness on the day of hCG administration on pregnancy outcome in the first fresh IVF/ICSI cycle. Gynecological Endocrinology. 2016 Jun 2;32(6):473-6. [Online Article Link]

[16] Ataalla WM, abd Elhamid T, Elhalwagy AE. Adjuvant sildenafil therapy in poor responders undergoing in vitro fertilization: A prospective, randomized, double-blind, placebocontrolled trial. Middle East Fertility Society Journal. 2016 Sep 1;21(3):1759. [Online Article Link]

[17] Mangal S, Mehirishi S. To study and compare the effect of vaginal sildenafil and estradiol valerate on endometrial thickness, blood flow and pregnancy rates in infertile women undergoing intrauterine insemination. Int J Reprod Contracept Obstet Gynecol. 2016; 5(7): 2274-2277. [Online Article Link]

[18] Margreiter M, Weghofer A, Feichtinger W. Vaginal sildenafil in patients with poor endometrial development undergoing in vitro fertilization. Fertil Steril. 2004; 82(2): S140. [Online Article Link]

[19] El-Shourbagy S, Ossman AM, ElMohamady A. The role of sildenafil citrate (viagra) suppositories on endometrial response (thickness and mean resistance index of endometrial spiral artery) in cases of unexplained infertility. Menoufia Medical Journal. 2017 Apr 1;30(2):343-394. [Online Article Link]

[20] Çetinkaya K, Kadanalı S. The effect of administering vaginal estrogen to clomiphene citrate stimulated cycles on endometrial thickness and pregnancy rates in unexplained infertility. Journal of the Turkish 
German Gynecological Association. 2012;13(3):157-161. [Online Article Link]

[21] Torres RF, Habana AE, Tansengco LG. The effect of estrogen supplementation on the endometrium and pregnancy rate among infertile women treated with clomifene citrate: a meta-analysis. Fertility and Sterility. 2005 Sep 1;84:S162-3. [Online Article Link]

[22] Golkar MH, Borujeni MJ, Rashidi

B. The Effects of Administrated Sildenafil Citrate on Uterine Luminal Epithelium Height Associated with Ovarian Angiogenesis:

An Experimental Animal Study. Advanced biomedical research. 2017;6:164. [Online Article Link]

[23] Trakakis E, Vaggopoulos V, Sioulas VD, Panagopoulos P, Grammatikakis I, Ambatzi P, Kassanos D. The contribution of sildenafil (Viagra) to ovarian stimulation with gonadotropins in a woman with poor ovarian response. Gynecological Endocrinology. 2014 Jul 1;30(7):47880. [Online Article Link]

\section{Authors Biography}

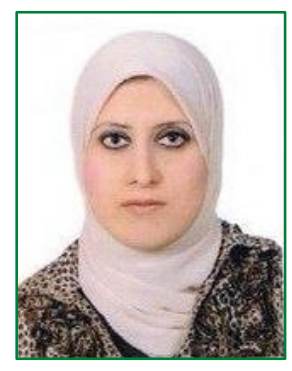

\section{Dr. Sundus Ali Dawood}

She received the M.B.CH.B. from the College of Medicine, Al-Mustansiriya University in 2005. She occupied the position of rotator house officer in AlYarmouk Teaching Hospital from 2006-2007. She worked in Baghdad during her permanency in obstetrics and gynecology 2008-2009. until the start of a residency program in 2009 at Baghdad Teaching Hospital and graduated as a specialist in Obstetrics and Gynecology in 2011 with an H.D of Obst. And Gyne. She worked as a specialist in General Hospital in Al-Anbar city from 2011-2017. From 2018-2020 graduated as a specialist in infertility with H.D from Al-Nahrain University, the High Institute for Infertility Diagnosis and Assisted Reproductive Technologies. Currently, she is attending Al Nahrain University, the High Institute for Infertility Diagnosis and Assisted Reproductive Technologies as a Ph.D. student.

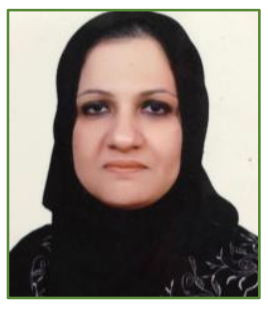

\section{Dr. Mufeda Ali Jwad}

She received her $\mathrm{MBChB}$. From the College of Medicine at the University of Baghdad in 1996. Her M.Sc. in Applied Embryology and her Ph.D. in Infertility and Clinical Reproduction were from the High Institute of Infertility Diagnosis and Assisted Reproductive Technologies, Al Nahrain University in 2007 and 2018 respectively. She worked as a rotator in the Baghdad health department from 1996-1999. She worked in Gyn. \& Obs. in Alsamawa general hospital and Babylon hospital from 2000-2003. She worked at the Babylon University, College of Medicine, anatomy and embryology department from 20032004. She has been working as a specialist physician and a consultant clinic at the High Institute of Infertility Diagnosis and Assisted Reproductive Technologies, Al Nahrain University from 2008-2015. Currently, she is an assistant professor and specialist in infertility and clinical reproduction. She is the head of the clinical reproductive physiology department from 2019 till now. She has more than 25 published articles in national and international journals. 


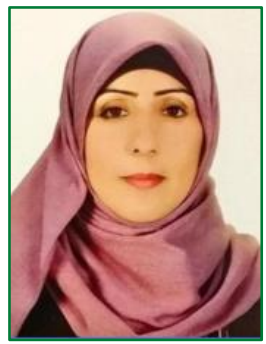

\section{Dr. Huda Ali Hussaini}

She received the M.B.Ch.B: Babylon University, College of Medicine, in 2000. The diploma in Radiology from the University of Baghdad in 2007. She is a fellow of the Iraqi Board for Medical Specialization, Council of Radiology since 2008. Currently, she is an assistant professor. Al Nahrain University, College of Medicine, department of surgery (specialist radiologist). She is a Member of staff in the high Institute of infertility diagnosis and ARTS. Including the ultrasound department in the institute since 2018. She has Participations in a lot of annual meetings, medical conferences. Seminars, continuous learning, and thesis discussion. She is a member of the Iraqi medical association, the Iraqi Society of Radiologists and medical imaging, the Iraqi Journal of Embryos infertility researches, European Society for Hybrid, Molecular, and translation imaging. She published more than 15 articles and has supervised many students.

\section{How to cite:}

Dawood SA; Jwad MA; Hussaini HA. A Comparison Between the Effect of Vaginal Sildenafil Versus Oral Estradiol Valerate on Ultrasound Parameters of Endometrial Receptivity and Follicular Growth in Iraqi Females Receiving Letrozole for Induction of Ovulation; Iraqi Journal of Embryos and Infertility Researches (IJEIR), (2020); 10(1): 35-50.

Doi: http://doi.org/10.28969/IJEIR.v10.i1.r3 in any medium or format, as long as you give appropriate credit to the original author(s) and the source, provide a link to the Creative Commons license, and indicate if changes were made. http://creativecommons.org/licenses/by/4.0/.

\section{(c) (7) $\odot 2020$ Author(s)}

This article is licensed under a Creative Commons Attribution 4.0 International License, which permits use, sharing, adaptation, distribution and reproduction 